\title{
ORALIDADE E VOCALIDADE NA POÉTICA DOS CANTADORES DE VIOLA: A POESIA DE CEGO SINFRÔNIO
}

\section{ORALITY AND VOCALITY IN THE VIOLA SINGERS POETIC: THE CEGO SINFRÔNIO POETRY}

Maria Elisalene Alves dos Santos ${ }^{16}$

\begin{abstract}
RESUMO: A presente pesquisa, de natureza bibliográfica, trata da cantoria manifestada no interior do Ceará. Objetiva investigar a respeito da oralidade e da vocalidade presentes nos versos dos cantadores de viola, de forma especial, nos versos do poeta conhecido por Cego Sinfrônio. Para tanto, discutiu-se, inicialmente, sobre o conceito de oralidade voltado para a poesia oral. No segundo momento, o estudo volta-se para a definição de vocalidade e sua importância no processo de realização da cantoria. Finalmente, as categorias de oralidade e de vocalidade são aplicadas aos versos de Cego Sinfrônio. A pesquisa teve o suporte teórico de Marchuschi (2010), Mota (2002), Zumthor (1993; 2010) entre outros. Espera-se que este trabalho possa contribuir com o processo de valorização e de reconhecimento da arte da cantoria.
\end{abstract}

PALAVRAS-CHAVE: Oralidade. Vocalidade. Cantoria. Cego Sinfrônio.

ABSTRACT: The present bibliographic research deals with the singing manifested in the countryside of Ceará. It aims to investigate the orality and the vocality in the verses of the viola singers, especially, in the verses of the poet known as blind Sinfrônio. Therefore, it was discussed, initially, the concept of orality focused on oral poetry. Secondly, the study deals with the definition of vocality and its importance in the process of performing the singing. Finally, the categories of orality and vocality are applied to the verses of blind Sinfrônio. The research had the theoretical support of Marchuschi (2010), Mota (2002), Zumthor (1993; 2010) among others. It is hoped that this work can contribute to the process of appreciation and recognition of the art of singing.

KEY WORDS: Orality. Vocality. Singing. Cego Sinfrônio.

\section{Introdução}

Os estudos sobre a poesia dos cantadores de viola vêm se ampliando de forma considerável no meio acadêmico. Tal fato reflete o valor dado às produções orais de importantes poetas que antes se mantinham no anonimato.

O tema deste trabalho, Oralidade e vocalidade na poética dos cantadores de viola: a poesia de Cego Sinfrônio, surge da necessidade de se realizar investigações acerca da poesia oral produzida por cantadores de viola do sertão cearense, em especial, por Cego Sinfrônio ${ }^{17}$. Desta forma, esta pesquisa apresenta como objetivo geral investigar aspectos de oralidade e de vocalidade nos versos produzidos por Cego Sinfrônio, um dos mais notáveis cantadores de viola do Ceará.

Esta pesquisa, de caráter bibliográfico, é organizada em três sessões. Na primeira, intitulada $A$ poética da oralidade, discorre-se sobre o conceito de oralidade tomando por base teórica Marchuschi (2010), Saussure (2012), Urbano (2006) e Zumthor (1993; 2000; 2010). Em seguida, na sessão nomeada A importância da voz, atem-se unicamente a Zumthor (1993; 2010) como referencial teórico. Até o momento, Zumthor (2010) apresenta-se como o principal estudioso que desenvolve pesquisa a respeito da voz, importante categoria no universo da poesia oral. Aqui, trata-se da pertinência da voz como elemento de autoridade no momento de declamação da poesia. É a voz que ressignifica o texto poético, promovendo uma

\footnotetext{
${ }^{16}$ Doutoranda em Linguística pelo Programa de Pós-Graduação em Linguística (PROLING/UFPB). Mestre em Literatura Brasileira pela Universidade Federal do Ceará. E-mail: elisalene2014@gmail.com

${ }^{17}$ Dentre as pesquisas realizadas, não constam informações precisas sobre a data de nascimento e de morte de Sinfrônio Pedro Martins, o Cego Sinfrônio. Provavelmente, ele tenha nascido por volta de 1880. Quanto ao ano de falecimento, nenhuma informação foi encontrada.
} 
extensão do poeta ao ouvinte. Discorre-se ainda sobre o conceito de vocalidade, termo criado por Zumthor (1993). Na última sessão, intitulada A poética dos cantadores de viola: a poesia de Cego Sinfrônio, aplica-se o conceito de oralidade e de vocalidade nos versos do poeta Sinfrônio, cantador de valor singular no contexto da cultura cearense. No desenvolvimento desta sessão, foram consultados os teóricos Barroso (2006), Mota (2002), Sautchuk (2009) e Zumthor (1993; 2010).

Por fim, espera-se que a presente pesquisa tenha relevância no âmbito acadêmico e, principalmente, possa contribuir para a valorização do acervo poético dos cantadores de viola do sertão cearense.

\section{A poética da oralidade}

Para se discutir sobre a questão da oralidade é importante que se realize, primeiramente, algumas considerações sobre o conceito de língua.

De acordo com Urbano (2006, p.23), a língua é utilizada para expressar a linguagem verbal, atividade criada pelo ser humano a fim de se comunicar com outros indivíduos. Ela é “[...] uma descoberta dos linguistas que entendem a linguagem verbal como um sistema de signos, atribuindo-lhe a denominação de 'língua', por metonímia ao órgão do corpo humano (língua), o qual é responsável pela articulação e realização sonora da própria linguagem". Ainda conforme Urbano (2006, p. 23), alguns linguistas compartilham "[...] do conceito de que a verdadeira natureza da língua é a oralidade".

Saussure (2012, p. 59), por exemplo, ao discutir sobre as causas do predomínio da escrita sobre a forma falada afirma que "A língua tem, pois, uma tradição oral independente da escrita e bem diversamente fixa; todavia, o prestígio da forma escrita nos impede de vê-lo". Para Saussure (2012), a palavra falada, por si só, constitui o objeto linguístico.

Reforçando o debate sobre a importância da oralidade como natureza da língua, cita-se Marcuschi (2010, p. 25). Este, ao discorrer sobre o conceito de oralidade, escreve que "A oralidade seria uma prática social interativa para fins comunicativos que se apresenta sob variadas formas ou gêneros textuais fundados na realidade sonora; ela vai desde uma realização mais informal à mais formal nos mais variados contextos de uso". Essa compreensão de oralidade converge com a manifestada na poética dos cantadores de viola.

Ao se tratar da oralidade, é pertinente que se faça referência ao medievalista, ao crítico literário e ao linguista suíço Paul Zumthor (1915-1995). Este teórico (2010, p.25) afirma que "[...] toda oralidade nos aparece mais ou menos como sobrevivência, reemergência de um antes, de um início, de uma origem". Ou seja, a importância da oralidade é concebida como ponto inicial, como origem para se explicar e se entender o que está sendo produzido na atualidade. A oralidade insiste em se fazer presente, oferecendo subsídios necessários de compreensão de diferentes valores. O referido teórico compreende oralidade:

[...] como um conjunto complexo e heterogêneo de condutas e de modalidades discursivas comuns, determinando um sistema de representações e uma faculdade de todos os membros do corpo social de produzir certos signos, de identificá-los e interpretá-los da mesma maneira; como - por isso mesmo - um fator entre outros de unificação das atividades individuais (ZUMTHOR, 1993, p. 22).

É válido ressaltar que Zumthor (1993), ao discorrer sobre oralidade, realiza relevantes estudos sobre a canção de gesta, escrita na Idade Média. É, aliás, a partir deste gênero poético medieval, que se coloca o problema sobre a poética da oralidade na França. São estudos concernentes, dentre outras questões, à natureza dos textos, à sua língua e às tradições locais. 
Para Zumthor (2000, p.102), “A 'poesia' da Idade Média [...] foi, no seu conjunto, como intenção, sempre de transmissão oral".

Apesar da resistência, diferentes trabalhos, na França, foram escritos ao longo do século XX sobre a poética da oralidade, tendo como ponto de partida a canção de gesta. Debruçavam-se sobre os condicionamentos externos da obra como a ação do recitador, distribuição das seções e inserção da vida social. No fim dos anos 70 , surgem estudos que passam a abordar a canção de gesta por via da música (ZUMTHOR, 1993).

Nesse ínterim, são levantados questionamentos sobre os equívocos surgidos na concepção e na definição do termo oralidade, visto por alguns pesquisadores como improvisação, da mesma forma, a falta de distinção clara entre tradição oral (referente à produção, conservação e repetição) e transmissão oral (diz respeito à própria transmissão e à recepção). Para Zumthor (1993, p.17), a tradição oral "[...] se situa na duração", enquanto que a transmissão oral se situa "[...] no presente da performance".

O autor também ressalta a dificuldade, ainda hoje, de se tentar interpretar a oralidade das tradições poéticas. Os estudiosos contentam-se apenas em observar sua existência quando, na verdade, deveria ser interrogada sobre sua natureza e suas funções próprias.

\section{A importância da voz}

Um dos teóricos que mais se debruça sobre a importância da voz nas tradições poéticas orais é Zumthor (2010). Este realiza, ao longo de suas pesquisas, considerações acerca da ausência de uma poética geral da oralidade que sirva de base teórica aos estudos da poesia transmitida pela voz.

Em suas investigações, o autor também propõe algumas discussões ao tratar da poética da voz a partir do seguinte questionamento "[...] há uma poeticidade oral específica?" (ZUMTHOR, 2010, p. 8). Ao lançar essa pergunta, Zumthor $(1993 ; 2010)$ tenta desenvolver uma possível resposta a partir de sua teoria sobre a importância da voz no universo da oralidade poética, enfocando as relações voz e linguagem, voz e emoção, voz e corpo, voz e poesia e voz e grupo social.

Ao tratar da relação da voz e linguagem, Zumthor (2010) ressalta a relevância da voz no desenvolvimento da linguagem, pois a voz é imprescindível à linguagem e esta é impensável sem aquela. É na linguagem que a poesia está enraizada. A linguagem vocalizada é chamada por Zumthor (2010, p. 8) de palavra; enquanto que "a linguagem sem a voz é a escrita". Por tudo isso, considera "[...] estranho que, entre todas as disciplinas instituídas, não haja ainda uma ciência da voz" (ZUMTHOR, 2010, p. 9), pois ela traria uma fundamentação teórica para o estudo da poesia oral.

Por conceber a voz como condutora da linguagem, em seus estudos, Zumthor (1993, p. 21) prefere utilizar a palavra vocalidade (que "é a historicidade de uma voz: seu uso") à oralidade. Segundo o referido autor, "Uma longa tradição de pensamento, é verdade, considera e valoriza a voz como portadora da linguagem, já que na voz e pela voz se articulam as sonoridades significantes" (ZUMTHOR, 1993, p. 21). O teórico afirma que a voz do poeta, ou do seu intérprete, lhe confere autoridade no momento em que ele canta ou recita (seja o texto improvisado, seja memorizado). Ou seja, quando o poeta canta os seus versos, o que predomina é o efeito vocal.

Este teórico reforça a discussão escrevendo que "A qualidade da voz constitui para o público um dos critérios, talvez o principal, da "poesia"”. E acrescenta: 
Volume 13 - Número 1 - mai/jul de 2018

particular - única. Nesse sentido, o texto só existe na razão das harmonias da voz (ZUMTHOR, 1993, p. 183).

Zumthor (2010, p.11, grifo do autor) afirma que "A voz se diz enquanto diz; em si ela é pura exigência. Seu uso oferece um prazer, alegria de emanação que, sem cessar, a voz aspira a reatualizar no fluxo linguístico que ela manifesta e que, por sua vez, a parasita". Ela está ligada às emoções, quando se manifesta através de um grito, representando uma lembrança, um desejo ou uma agonia.

A voz também está relacionada ao corpo, promovendo a imagem de um corpo vocal. A esse respeito, escreve Zumthor (2010, p.12), "Um corpo que fala está aí representado pela voz que dele emana, a parte mais suave deste corpo e a menos limitada, pois ela o ultrapassa, em sua dimensão acústica muito variável, permitindo todos os jogos". Nessa relação voz e corpo, o corpo em movimento pertence ao mundo visual e tátil, enquanto a voz ao universo sonoro. Esta transmite informações a respeito de alguém através do corpo que a emitiu e "[...] mais do que por seu olhar, pela expressão do seu rosto, uma pessoa é "traída por sua voz"' (ZUMTHOR, 2010, p. 13).

No capítulo O empenho do corpo, no livro Perfomance, recepção, leitura, Zumthor (2000, p. 81) desenvolve seis teses que tratam dos aspectos peculiares da voz. Especificamente, na quarta tese, o autor assevera que "[...] a voz é uma subversão ou uma ruptura da clausura do corpo. Mas ela atravessa o limite do corpo sem rompê-lo; ela significa o lugar de um sujeito que não se reduz à localização pessoal. Nesse sentido, a voz desaloja o homem do seu corpo". Ao libertar o homem do seu corpo, a voz passa a habitar a linguagem. Embora que, posteriormente, retorne para o corpo, pois ela emana dele. Por isso Zumthor afirma (2000, p. 82) que "A voz repousa no silêncio do corpo". Voz, corpo e linguagem estão diretamente ligados. Desta forma, pode-se considerar, então, que a voz situa-se entre o corpo e a palavra (linguagem).

Além da ligação voz e linguagem, voz e emoção, voz e corpo, Zumthor (2010, p. 178) discorre sobre a relação voz e poesia. De acordo com o referido autor, "O desejo da voz viva habita toda poesia, exilada na escrita". É através da voz que a poesia se manifesta, se engrandece e se avigora, pois, no dizer de Zumthor (2010), "O poeta é voz". O mesmo não acontece com a poesia escrita, ao contrário, na poesia escrita a voz é expatriada. O autor prossegue a discussão afirmando que "Toda poesia aspira a se fazer voz; a se fazer, um dia, ouvir: a capturar o individual incomunicável, numa identificação da mensagem na situação que a engendra, de sorte que ela cumpra um papel estimulador, como um apelo à ação" (ZUMTHOR, 2010, p. 179). Desta forma, justifica-se em diferentes lugares do mundo a voz do poeta ser bastante trabalhada. É o caso dos repentistas que habitam o sertão do Brasil. Sobre o valor da voz na poesia, Zumthor (2010, p. 179) reitera:

Desde seu jorrar inicial, a poesia aspira, como a um propósito ideal, a se depurar das limitações semânticas, a sair da linguagem, ao alcance de uma plenitude, onde tudo que não seja simples presença será abolido. A escrita reprime ou esconde essa aspiração. A poesia oral, ao contrário, acolhe seus fantasmas e tenta lhes dar forma.

Ou seja, a poesia, por sua natureza, almeja à liberdade somente encontrada na oralidade através da voz do poeta. É na voz do poeta que a poesia se torna plena, pois é a voz poética que dá forma aos espectros que rondam a poesia, diferentemente da escrita, que a reprime.

Vale ressaltar também o efeito produzido pela voz no ato da declamação. De acordo com Zumthor (1993), a voz do poeta, ou do seu intérprete, lhe confere autoridade no momento em que ele canta ou recita (seja o texto improvisado, seja memorizado). Isso significa que quando o poeta canta os seus versos, o que predomina é o efeito vocal. A voz do 
poeta, mais do que o texto escrito, exerce um valor que extrapola os limites da interpretação poética. Ela promove no ouvinte a capacidade de criar, de inventar e de imaginar. A formação de um universo simbólico, pode-se dizer, é possível pelo poder que a voz do poeta exerce sobre o ouvinte. A respeito dos efeitos produzidos pela poesia transmitida pela voz, escreve Zumthor (1993, p. 71):

A palavra poética vocalmente transmitida dessa forma, reatualizada, reescutada,
mais e melhor do que teria podido a escrita, favorece a migração de mitos, de temas
narrativos, de formas de linguagem, de estilos, de modas, sobre áreas às vezes
imensas, afetando profundamente a sensibilidade e as capacidades inventivas de
populações que, de outro modo, nada teria aproximado.

Ressalte-se ainda a força exercida pela voz sobre o poeta. Este, de forma inconsciente, é possuído pela voz que o domina. Ao ser tomado pela voz, o poeta traduz os sentimentos do público e oferece respostas aos seus anseios. O poeta torna-se então onipresente. Quando isso acontece, a voz revela-se com o aspecto de universalidade, segundo afirma Zumthor (1993, p. 74, grifo do autor) no excerto abaixo:

Em maior ou menor medida, todo jogral, menestrel, recitador, leitor público
carrega uma voz que o possui mais do que ele a domina: à sua própria maneira,
ele interpreta o mesmo querer primordial do padre ou juiz. [...] Mas a variedade
das palavras que ele tem por missão pronunciar diante de um grupo, sua aptidão
particular para refletir (exaltando-a) a diversidade da experiência humana, para
responder às demandas sociais - essa dutilidade essa onipresença conferem à
voz do intérprete, em sua plena realidade fisiológica, uma aparência de
universalidade [...]. No caleidoscópio do discurso que faz o intérprete de poesia
na praça do mercado, na corte senhorial, no adro da igreja, o que se revela
àqueles que o escutam é a unidade do mundo. Os ouvintes precisam de tal
percepção para sobreviver.

Com a citação mencionada, reforça-se a relevância da voz do intérprete. Ela alimenta a imaginação do ouvinte que, por sua vez, precisa dela "para sobreviver".

Enquanto condição de sobrevivência, a voz poética é destacada por Zumthor (1993, p. 139) ao afirmar que ela "[...] assume a função coesiva e estabilizante sem a qual o grupo social não poderia sobreviver". Ou seja, a voz poética promove a união e a estabilidade em um grupo social que sobrevive porque dela se alimenta. Ela "[...] está presente em toda parte, conhecida de cada um, integrada nos discursos comuns, e é para eles referência permanente e segura" (ZUMTHOR, p. 139).

O referido teórico ainda acrescenta: “[...] A voz poética é, ao mesmo tempo, profecia e memória" (ZUMTHOR, p. 139). Além de ocasionar coesão, harmonia, solidez e segurança, a voz poética também assume o caráter profético, revelando o que está por vir. Ao mesmo tempo, ela é a memória (mnemosine) e o registro vivo do passado de um grupo social. Sendo mnemosine, a voz preserva do esquecimento os grandes acontecimentos e os eterniza.

Da mesma forma, Ferreira (1993), uma das principais estudiosas da obra de Zumthor, ao discorrer sobre a importância da voz poética nos estudos de Zumthor, afirma que um aspecto caracterizador da poesia medieval é sua proximidade com o grande público. O olhar e o gesto integram essa poesia. A estes, une-se um terceiro elemento, a voz. Para a referida autora, "A voz geraria a terceira dimensão deste espaço para uma sociedade praticamente analfabeta [...]" (FERREIRA, 1993, p. 288).

As discussões realizadas acima sobre oralidade e vocalidade vêm corroborar com a análise dos versos de cego Sinfrõnio que se apresentam na sessão seguinte. 


\section{A poética dos cantadores de viola do sertão cearense: a poesia de Cego Sinfrônio}

É sobre a poesia dos cantadores de viola de que trata esta sessão, de forma específica, sobre a poesia de Sinfrônio Pedro Martins, o Cego Sinfrônio. Sinfrônio nasceu em Messejana, um bairro de Fortaleza-CE, por volta de 1880.

A produção poética dos cantadores de viola manifesta-se de maneira oral. A respeito da poesia oral, escreve Zumthor (2010, p.84): "[...] a poesia oral geralmente comporta mais e mais complexas regras do que a escrita: nas sociedades de forte predominância oral, ela constitui, muitas vezes, uma arte muito mais elaborada do que a maior parte dos produtos de nossa escrita".

A poesia oral dos cantadores de viola realiza-se em formato de cantoria. Discorrendo sobre o gênero cantoria, Zumthor (2010, p. 109) afirma que é uma “[...] disputa estilizada, em princípio improvisada mas estreitamente regulada, destinando-se a valorizar a virtuosidade dos poetas". Mesmo acontecendo de forma improvisada, um dos princípios que rege a cantoria, ela não deixa de respeitar suas regras próprias. Esse procedimento promove a virtuosidade do poeta.

Para Sautchuk (2012, p. 15), “O termo 'cantoria' designa o gênero poético-musical, a situação de sua apresentação e o campo social formado por cantadores e seus ouvintes". Integram a cantoria "habilidades de composição e apresentação". Estas habilidades, ainda de acordo com Sautchuk (2012, p. 24), são "Mais do que técnicas de composição poética, canto e execução instrumental". Elas "[...] dizem respeito a estratégias de relação com o outro cantador, com a plateia, com as normas poéticas, com conhecimentos, com modelos cognitivos".

Acrescem-se a essa discussão, algumas definições sobre o cantador, o responsável por ecoar a voz que se concretiza em forma de poesia. De acordo com Leonardo Mota, importante estudioso cearense e entusiasta da arte de versejar, os cantadores são "[...] poetas populares que perambulam pelos sertões, cantando versos próprios e alheios; mormente os que não desdenham ou temem o desafio, pela peleja intelectual em que, perante o auditório ordinariamente numeroso, são postos em evidência os dotes de improvisação de dois ou mais vates matutos" (MOTA, 2002, p 3).

Além de Leonardo Mota, registra-se o nome de outro pesquisador da poesia oral, Gustavo Barroso. Este define a poesia como a mais completa manifestação artística do sertão, que se apresenta sob dois aspectos: o repentista e o tradicional. Interessa a este trabalho o repentista que é afinado em desafios, em glosas e em quadras líricas, elegíacas e amorosas (BARROSO, 2006). Quanto ao tradicional, recita poemas alheios.

Zumthor (1993) utiliza o termo intérprete para o cantador da poesia oral, ressaltando que sua condição de intérprete equivale a uma "presença". Para Zumthor (1993, p. 71), o intérprete da poesia oral "[...] é, em face de um auditório completo, o 'elocutor concreto' de que falam os pragmatistas de hoje; é o "autor empírico" de um texto cujo autor implícito, no instante presente, pouco importa, visto que a letra desse texto não é mais letra apenas, é o jogo de um indivíduo particular, incomparável".

No Brasil, conforme Sautchuk (2012), é na região nordeste, especialmente no sertão nordestino, que as cantorias mais se desenvolvem. Quatro são os estados onde se nota o maior registro de cantadores: Pernambuco, Paraíba, Rio Grande do Norte e Ceará. São oriundos desses estados os mais famosos cantadores como Raulino Silva, Ivanildo Vila Nova, Edmilson Ferreira, Antonio Lisboa, Geraldo Amâncio dentre outros. No Nordeste, subsiste uma oralidade que pode ter durado mais de dois séculos.

Os gêneros poéticos comumente utilizados pelos cantadores da época eram, ainda de acordo com Mota (2002), obras de seis, sete ou oito pés (sextilhas de versos de sete sílabas, obra é qualquer estrofe e pé é o verso); o moirão (pode ser de cinco ou sete pés); o 
martelo (descante de toada rápida, preferido para as pelejas violentas, feito, geralmente, em décimas); a obra de nove-por-seis (estrofe de nove versos, dos quais seis têm sete sílabas, os três restantes - o segundo, o quinto e o oitavo - têm três); a ligeira (quadra bipartida, de versos de sete sílabas, com a rima obrigatória em á e precedida do refrão "Ai, d-a- dá"); o quadrão (quando em vez de dois, se canta alternativamente só um verso); o gabinete (décima de versos de dez sílabas); o galope (sextilha de decassílabos); a embolada (décima de versos de cinco sílabas); e, por fim, o dez pés em quadrão (décima de versos de sete sílabas). (MOTA, 2002)

É com as estrofes a seguir, de Cego Sinfrônio, o exemplo que se registra do talento e da espontaneidade dos versos dos cantadores de viola. Elas compõem um extenso poema apresentado a Leonardo Mota quando da primeira vez que esteve em sua casa:

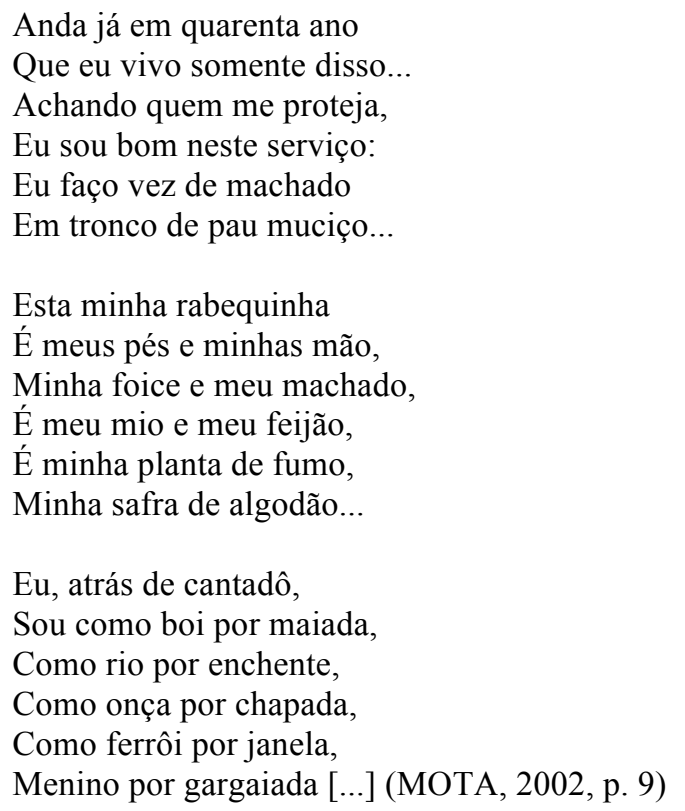

A fim de se emitir alguma interpretação sobre os versos acima, retoma-se os estudos de Zumthor (1993), sobre a oralidade das tradições poéticas. O teórico traça três observações com o intuito de elucidar essa discussão. Na primeira, ele distingue três tipos de oralidade, correspondentes a três situações de cultura: a "primária e imediata, que não comporta nenhum contato com a escrita"; a oralidade mista, "quando a influência do escrito permanece externa, parcial e atrasada"; e, finalmente, a oralidade segunda, "quando se recompõe com base na escritura num meio onde esta tende a esgotar os valores da voz no uso do imaginário". Ou seja, a oralidade mista "[...] procede da existência de uma cultura 'escrita' (no sentido de 'possuidora de uma escritura'); e a oralidade segunda, de uma cultura 'letrada' (na qual toda expressão é marcada mais ou menos pela presença da escrita)" (ZUMTHOR, 1993, p.18).

Na segunda observação, Zumthor (1993) escreve que em uma sociedade conhecedora da escritura, todo texto poético, à medida que visa a transmissão ao público, realiza-se seja por via sensorial (oral-auditiva), seja por uma inscrição oferecida à percepção visual, ou, ainda, por esses dois procedimentos ao mesmo tempo.

Por fim, na terceira observação, o teórico afirma que a voz do poeta, ou do seu intérprete, lhe confere autoridade no momento em que ele canta ou recita (seja o texto improvisado, seja memorizado). Ou seja, quando o poeta canta os seus versos, o que predomina é o efeito vocal. Daí Zumthor (1993, p.19) preferir utilizar a palavra vocalidade à oralidade. A vocalidade "[...] é a historicidade de uma voz: seu uso. Uma longa tradição de pensamento, é verdade, considera e valoriza a voz como portadora da linguagem, já que na voz e pela voz se articulam as sonoridades significantes". Zumthor (1993, p. 183), reforça a 
discussão escrevendo que "A qualidade da voz constitui para o público um dos critérios, talvez o principal, da "poesia"'. E acrescenta:

Modulado de modo a levar em conta pesadas coerções sintáticas provenientes do texto, submetendo-as a sua ordem própria, o ritmo vocal comporta uma curva melódica que valoriza e que comunica, segundo as circunstâncias, uma qualidade particular - única. Nesse sentido, o texto só existe na razão das harmonias da voz (ZUMTHOR, 1993, p. 183).

Partindo-se da discussão acima, volta-se às estrofes de Cego Sinfrônio, cantador e tocador de rabeca "como os menestréis medievais", no dizer de Mota (2002). Ele cegou quando tinha um ano de idade. Manteve na memória uma grande quantidade de romances, cantigas e desafios. É a esposa "[...] que lhe lê, pacientemente, manuscritos e folhetos até que ele os consiga recitar" (MOTA, 2002, p.9). Sinfrônio foi também um habilidoso improvisador. Ao analisar seus versos, considerando a sua condição de cego e analfabeto, pode-se afirmar que a oralidade presente nos versos é a mista pois neles identificamos dois elementos discutidos por Zumthor (1993), a coexistência com a escritura, no seio de um grupo social, e a influência do escrito permanecer externa.

É pertinente considerar ainda nos versos de Sinfrônio o efeito vocal no momento da sua declamação. Os versos são recitados para Leonardo Mota que, após ouvi-los, reafirma seu encantamento pela poesia do poeta. Este efeito vocal, provocado pelo cantador no ato da recitação, está diretamente relacionado ao conceito de performance. Zumthor (2000, p.51, grifos do autor) define performance como:

Termo antropológico e não histórico, relativo, por um lado, às condições de expressão, e da percepção, por outro, performance designa um ato de comunicação como tal; refere-se a um momento tomado como presente. A palavra significa a presença concreta de participantes implicados nesse ato de maneira imediata.

Nesse sentido, é verdadeiro afirmar que a realização da performance poética exige a atenção do ouvinte. Desta forma, ela pode ser compreendida como uma ação que desempenha plenamente a função da linguagem denominada por fática, jogo de aproximação e de apelo, de provocação do outro, nas palavras de Zumthor (1993). Por isso se explica o porquê da poesia oral exigir um ouvinte-espectador para que se realize o efeito pleno da performance. Os versos, a seguir, de Sinfrônio, exemplificam bem a discussão acima:

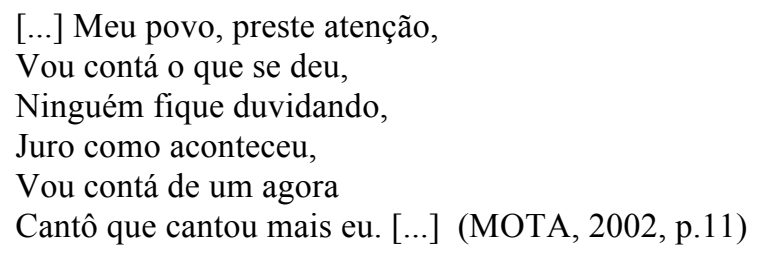

Declamados para Leonardo Mota, os versos avisavam-no que iria falar de algo que the acontecera. Trata da peleja que tivera com Manuel Passarinho, ágil repentista com dotes de improvisador. Logo no primeiro verso, Sinfrônio reclama a atenção do ouvinte "Meu povo, preste atenção". Sua voz provoca o espectador, produzindo o imediato efeito performático. Ao receber os versos cantados pela voz do poeta, o ouvinte adere a esse discurso. A obra performatizada transforma-se em diálogo, ainda que somente um participante (Cego Sinfrônio) tenha a palavra. Seria o diálogo sem dominante nem dominado, considerado uma troca livre pois "[...] a comunicação oral não pode ser monólogo puro: ela requer imperiosamente um interlocutor, mesmo se reduzido a um papel silencioso" (ZUMTHOR, 1993, p.22). 
Quanto aos traços linguísticos encontrados nos versos de Sinfrônio, e considerando-o como enunciador que não teve acesso à língua gramaticalizada, destacam-se as palavras contá e cantô, no segundo, quinto e sexto versos. Apesar de o cantador não pronunciar as palavras gramaticalmente corretas, utiliza-se da língua coloquial predominante na fala (o fonema /r/ final não é marcado), porém o sentido se mantém inalterado. O ouvinte compreende com clareza que o cantador que o adverte irá narrar algo inusitado de outro poeta que o desafiou em uma cantoria. Com isso, pode-se perceber que Sinfrônio utilizou as suas próprias regras de funcionamento da língua portuguesa, e sua fala não comprometeu o seu objetivo final, a comunicação com o espectador.

Ressalte-se que com o mesmo talento de Sinfrônio, havia um número considerável de jograis cegos, notáveis em toda a Europa, até os séculos XV, XVI e XVII. Eram detentores de um repertório que se tornou conhecido, em Espanha e em Portugal, por arte de ciego, romances de ciegos (ZUMTHOR, 1993). No Nordeste, mais precisamente no sertão nordestino, com o passar dos anos, o número de cantadores cegos diminuiu. Durante dois ou três séculos, os cegos de feira percorreram todo o interior do país, levando a sua arte.

Assim como o cego Sinfrônio, um outro exemplo é o cego Aderaldo, nascido no Crato e considerado um dos mais talentosos da sua geração. Morreu em 1967, após ter, quatro anos antes, publicado suas memórias (ZUMTHOR, 2010).

\section{Considerações finais}

As produções acadêmicas em torno da poesia oral produzida no sertão cearense vêm aumentando consideravelmente. Há muito se identificam estudos relevantes sobre os cantadores de viola, principalmente, do final do século XIX e início do XX. Entretanto, assim como se está longe de ser inédita esta pesquisa, também muito distante se está de encerrar o assunto.

Foi partindo do pensamento acima que se desenvolveu este trabalho sobre a poética do Cego Sinfrônio. Inicialmente, discutiu-se sobre a importância da oralidade como prática social e seu papel no contexto linguístico cultural dos cantadores de viola. Constatouse que o cantador, ao expressar-se por meio da linguagem oral, concebida como instrumento de comunicação e interação social, ressignifica a palavra poética, proporcionando ao ouvinte formas de encantamento poético do imaginário popular.

Quanto à pertinência da voz no estudo da poesia oral, percebeu-se que o processo de construção poética dos cantadores se produz por meio da palavra oral e se concretiza eficazmente com a contribuição sensorial própria da voz. É a voz do cantador que lhe dá autoridade no momento em que recita os seus versos. Esse feito vocal exercido pela voz do recitador promove no ouvinte um universo de imagens significantes.

Finalmente, foram aplicados os conceitos de oralidade e de vocalidade nos versos de Cego Sinfrônio. Este manifesta seu talento por meio de uma linguagem poética variada, de uma versificação autêntica, afetando, de forma profunda, a sensibilidade e a capacidade inventiva do ouvinte. Nos versos desse poeta, que são proferidos de maneira improvisada, constatou-se a espontaneidade e a proeza em incitar a atenção do seu público, que reage de forma imediata a sua declamação.

Espera-se que, com o desenvolvimento desta pesquisa, possa-se contribuir, de forma relevante, para os estudos sobre a oralidade dos cantadores de viola do Ceará e para a importância deste gênero poético na atual conjuntura de resgate e valorização da cultura oral. 


\section{REFERÊNCIAS}

BARROSO, Gustavo. Terra de Sol. $8^{\text {a }}$ ed. Apresentação de Braga Montenegro. Rio - São Paulo - Fortaleza: ABC Editora, 2006.

FERREIRA, Jerusa Pires. A Letra e a Voz de Paul Zumthor (Posfácio). In: ZUMTHOR, Paul. A letra e a voz: A "literatura" medieval. (Trad. Amálio Pinheiro e Jerusa Pires Ferreira). São Paulo: Companhia das Letras, 1993.

MARCUSCHI, Luiz Antonio. Da fala para a escrita: atividades de retextualização. 10. ed. São Paulo: Cortez, 2010.

MOTA, Leonardo. Cantadores. 7ª ed. Rio - São Paulo - Fortaleza: ABC Editora, 2002.

SAUTCHUK, João Miguel. A poética do improviso: prática e habilidade no repente nordestino. Brasília: Editora Universidade de Brasília, 2012.

SAUSSURE, Ferdinand de. Curso de Linguística Geral. $28^{\mathrm{a}}$ ed. São Paulo: Cultrix, 2012. URBANO, Hudinilson. Usos da linguagem verbal. In: PRETI, Dino (Org.). Oralidade em diferentes discursos. São Paulo: Associação Editorial Humanitas, v. 8, no 1, p. 19-55, 2006. ZUMTHOR, Paul. A letra e a voz: A "literatura" medieval. Trad. Amália Pinheiro, Jerusa Pires Ferreira. São Paulo: Companhia das Letras, 1993.

Paulo: EDUC, 2000.

Performance, recepção e leitura. Trad. Jerusa Pires Ferreira, Suely Fenerich. São

Introdução à poesia oral. Trad. de Jerusa Pires Ferreira, Maria Lúcia Diniz Pochat, Maria Inês de Almeida. Belo Horizonte: Editora UFMG, 2010. 